\title{
Characterization and comparison of yeasts from different sources for some probiotic properties and exopolysaccharide production
}

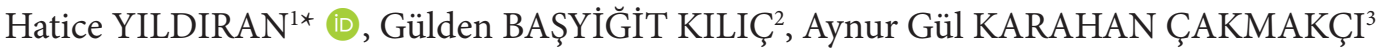

\begin{abstract}
A total of 134 strains of yeasts isolated from fruits and vegetables (certain berry fruits, apples, pomegranates, carrots and grapes), free-range chicken feces and dairy products, and from 10 commercial yeast preparations were identified and subjected to analyses to determine their in vitro probiotic properties. Based on $26 \mathrm{~S}$ rRNA sequence analysis all ten isolates from commercial products were identified as Saccharomyces cerevisiae, and the natural isolates as Candida corpophila, Candida diddensiae, Clavispora lusitaniae, Hanseniaspora opuntiae, Hanseniaspora uvarum, Kazachstania bovina, Kluyveromyces marxianus, Metschnikowia. pulcherrima, Metschnikowia sp., Meyerozyma carribbica, Pichia kluyveri and Wickerhamomyces anomalus. All isolates were found to be resistant to simulated gastric juice at $\mathrm{pH} 2.5$ for $2 \mathrm{~h}$ and were able to grow at both 30 and $37^{\circ} \mathrm{C}$. The exopolysaccharide (EPS) production of isolates from commercial preparations and from natural sources varied between 249-275.22 and 27.95$272.22 \mathrm{mg} / \mathrm{L}$, respectively. Two of the natural isolates had levels of EPS production comparable to the natural strains (S. cerevisiae T8-3C and S. cerevisiae P25-1) with 264.63 and $272.53 \mathrm{mg} / \mathrm{L}$, respectively. Isolates were also investigated for autoaggregation and coaggregation abilities. The highest coaggregation ability was determined for the Saccharomyces cerevisiae P25-1 strain against Staphylococcus aureus (ATCC 25923).
\end{abstract}

Keywords: probiotic yeasts; autoaggregation; production; gastric survival; isolation.

Practical Application: Characterization of novel yeast strains from different sources and determination of their some probiotic properties.

\section{Introduction}

As the food industry continues developing new products and processes, consumers are focused on the food safety, diet and health aspects of their food. Yeasts are important microorganisms in the fermentation of foods and beverages, and some yeasts have been used as biocontrol agents and novel probiotics (Fleet, 2007). During the last decades, since they have shown numerous beneficial effects on human health, their usage as probiotics has been increasing (Gil-Rodríguez et al., 2015). Probiotics are desirable and natural tools to providing balance to the intestinal microflora. They are consumed either as food or non-food preparations. New species of probiotics are constantly being identified (Gotcheva et al., 2002). Although most studies and applications of microbial benefits have focused on lactic acid bacteria (LAB), considerable efforts have also beeen directed towards researching yeasts for their beneficial effects (Muccilli \& Restuccia, 2015; Suvarna et al., 2018).

Probiotic yeasts are non-pathogenic strains generally belonging to species of Saccharomyces cerevisiae (Rajkowska \& Kunicka-Styczynska, 2010; Fakruddin et al., 2017). For yeasts intended to be used as probiotics, each strain must be characterized in vitro and in vivo (Moslehi-Jenabian et al., 2010; Suarez \& Guevara, 2018). Among the yeast used as probiotics strains must have the ability to show acid tolerance, bile resistance and inhibition of the pathogen adhesion to mucus and epithelial cells (Food and Agriculture Organization of the United Nations, 2002). Exopolysaccharides (EPSs) are produced by some yeast species, and some of these polysaccharides are useful in the food, cosmetic and pharmaceutical industries due to their specific physico-chemical and rheological properties (Pavlova et al., 2004; Kuncheva et al., 2007).

Some different yeast species such as Debaryomyces hansenii, Torulaspora delbrueckii, Kluyveromyces lactis, Kluyveromyces marxianus and Kluyveromyces lodderae have shown the ability to survive in the gastrointestinal tract and to inhibit enteropathogens (Moslehi-Jenabian et al., 2010). S. cerevisiae var. boulardii is a species most often used as a probiotic (Gil-Rodríguez et al., 2015), and is reported to be efficacious in the prevention or the recurrence of antibiotic associated diarrhea and colitis in humans (Van der Aa Kühle et al., 2005). Numerous in vitro and in vivo studies indicated that $S$. boulardii can prevent severe diarrhea and enterocolitis induced by a range of enteric bacteria (Hu et al., 2018). These pathogens are Clostridium difficile, Vibrio cholerae, Salmonella enterica subsp. enterica serovar Typhi (Salmonella Typhimurium), Shigella flexneri, enterohemorrhagic Escherichia coli and enteropathogenic E. coli (Chen et al., 2013; Syal \& Vohra, 2013; Xu et al., 2018). 
In this study, isolation, characterization, and identification of yeast strains from natural sources and retail cultures were investigated. Some probiotic properties of the isolates were determined. The tested strains were compared with retail yeast strains with in vitro setting for preselection for future researches.

\section{Materials and methods}

\subsection{Isolation}

Sixteen samples were prepared from natural sources as fruits and vegetables (certain berry fruits, apples, pomegranates, carrots and grapes), fourteen from free-range chicken feces, four from dairy products and ten commercial yeast preparations were used for isolation. Each sample was first homogenized in sterile phosphate saline (PBS); $\mathrm{pH}$ 7.0. Samples were spread on malt-extract glucose yeast-extract-peptone (MGYP) agar and plates were incubated at $30{ }^{\circ} \mathrm{C}$ for $48 \mathrm{~h}$. After incubation, isolated colonies were propagated for simple staining microscopic observation, and the cultures were maintained in MGYP broth with $15 \%$ glycerol at $-20{ }^{\circ} \mathrm{C}$ (Syal \& Vohra, 2013).

\subsection{Growth at 30 and $37^{\circ} \mathrm{C}$ and determination of EPS production}

Yeast isolates were screened for growth at two different temperatures and for qualitative analysis of EPS production. Cultures activated by two transfers in MGYP broth were inoculated at $1 \%$ and then were incubated at 30 and $37^{\circ} \mathrm{C}$ for $2-5$ days. Growth was evaluated by visual observation (Psomas et al., 2001). EPS production was conducted according to Sourabh et al. (2011) and Syal \& Vohra (2013). Overnight cultures were streaked on the surface of ruthenium red milk agar and Petri plates were incubated at $37^{\circ} \mathrm{C}$ for $24 \mathrm{~h}$. Non-ropy strains formed red colonies as a result of the staining of the microbial cell wall, while ropy isolates producing EPSs formed white colonies.

\subsection{DNA extraction and genotypic characterization}

DNA extractions were performed according to GarcíaHernández et al. (2012). The D1/D2 variable domains of the large subunit of the 26S rRNA gene were amplified by PCR using the primers; NL-1 (5'-GCATATCAATAAGCGGAGGAAAAG-3'), NL-4(5'-GGTCCGTGTTTCAAGACGG-3') (Kawahata et al., 2007; Moradi et al., 2018). Sequencing of the D1/D2 domains was performed directly from purified PCR products, and the sequences obtained were compared with those included in the GenBank database using the Basic Local Alignment Search Tool (BLAST) (National Center for Biotechnology Information, 2018).

\subsection{Determination of probiotic properties}

Survival in gastric juice

Activated cells were collected by centrifugation $(7,000 \mathrm{~g}$, $15 \mathrm{~min}$.) and inoculated at the level of approx. $10^{6} \mathrm{CFU} / \mathrm{mL}$ in a simulated gastric juice prepared according to Corcoran et al. (2005) and Cassanego et al. (2017). After incubation of yeast cultures for $18 \mathrm{~h}$ in $25 \mathrm{~mL}$ MGYP broth, the cultures were centrifuged at 7,000 $\mathrm{g}$ at $4{ }^{\circ} \mathrm{C}$ for $15 \mathrm{~min}$, washed once in an equal volume of cold 1/4 Ringer's solution and centrifuged under the same conditions. Pellets were then resuspended in a volume of simulated gastric juice equal to the original culture and incubated at $37^{\circ} \mathrm{C}$ for $2.5 \mathrm{~h}$ with constant stirring. Then samples were serially diluted in maximum-recovery diluent, plated on MGYP agar, and incubated at $37^{\circ} \mathrm{C}$ for $48 \mathrm{~h}$. The survival rate was calculated as the percentage of colonies observed on MYPG agar after exposure to $\mathrm{pH} 2.5$ for $2 \mathrm{~h}$ compared to the initial cell concentration (Corcoran et al., 2005).

\section{Autoaggregation assay}

The cells were harvested by centrifugation at $5,000 \mathrm{~g}$ for 15 min, washed twice and resuspended in PBS to obtain viable counts of approximately $10^{6} \mathrm{CFU} / \mathrm{mL}$. Cell suspensions $(4 \mathrm{~mL})$ were mixed by vortexing for $10 \mathrm{~s}$ and autoaggregation was determined during $5 \mathrm{~h}$ of subsequent incubation at room temperature. Every hour $0.1 \mathrm{~mL}$ of the upper suspension was transferred to another tube with $3.9 \mathrm{~mL}$ of PBS and the absorbance (A) was measured at $600 \mathrm{~nm}$. The autoaggregation percentage is expressed as Equation 1:

$\%$ Autoaggregation $=\left[1-\left(\right.\right.$ At/ $\left.\left.A_{0}\right)\right] \times 100$

where: At represents the absorbance at time 1, 2, 3, 4 or $5 \mathrm{~h}$ and $\mathrm{A}_{0}$ the absorbance at $\mathrm{t}_{0}$ (Kos et al., 2003). Percentage values of autoaggregation $<30 \%$ were considered low, between $30 \%$ and $60 \%$ intermediate, and $>60 \%$ high at room temperature for $2 \mathrm{~h}$. This assay was performed in duplicate (Binetti et al., 2013).

\section{Coaggregation assay}

The method for preparing the cell suspensions for coaggregation was the same as that for the autoaggregation assay. For determining coaggregation properties Staphylococcus aureus (ATCC 25923), Listeria monocytogenes (RSKK 472), E. coli O157:H7 (ATCC 35150), and S. Typhimurium (ATCC 700408) were used. Equal volumes $(2 \mathrm{~mL})$ of bacteria and yeast cell suspensions were mixed together in pairs by vortexing for $10 \mathrm{~s}$. Control tubes were set up at the same time, each containing $4 \mathrm{~mL}$ of yeast or bacteria suspension alone. The absorbance (A) at $600 \mathrm{~nm}$ of the suspensions was measured after mixing and after $5 \mathrm{~h}$ of incubation at room temperature. Samples were taken the same way as in the autoaggregation assay. The percentage of coaggregation was calculated using the Equation 2:

$\%$ Coagregation: $\frac{\left(A_{X}+A_{Y} / 2\right)-A_{(x+y)}}{A_{X}+A_{Y} / 2}$

where: $\mathrm{x}$ and $\mathrm{y}$ represent each of the two strains in the control tubes, and $(x+y)$ the mixture (Kos et al., 2003). Percentage values of coaggregation $<30 \%$ were considered low, between 30 and $60 \%$ intermediate, and $>60 \%$ high, at room temperature for $3 \mathrm{~h}$. This assay was performed in duplicate (Binetti et al., 2013).

\section{Quantitative analysis of EPS production}

Overnight cultures were heated at $100^{\circ} \mathrm{C}$ for $5 \mathrm{~min}$ and then centrifuged at $5,000 \mathrm{~g}$ for $10 \mathrm{~min}$ at $20^{\circ} \mathrm{C}$. The supernatant was removed, and the pellet was suspended in $1 \mathrm{~mL}$ of $85 \%(\mathrm{w} / \mathrm{v})$ TCA and centrifuged again. Aqueous phases were decanted, and 
the pellet suspended in $1 \mathrm{~mL}$ ethanol, washed twice more with ethanol, and the final pellet was dissolved in $1 \mathrm{~mL}$ of distilled water (Marshall \& Rawson, 1999). The phenol sulfuric acid colorimetric test for polysaccharides was used and the amount of EPSs determined in terms of glucose according to the glucose standard curves (Dubois et al., 1956).

\section{Results and discussion}

\subsection{Isolation, preselection and identification}

Natural and commercial yeast samples were plated on MGYP agar plates as described above. In all, 144 yeasts were selected from agar plates prepared from 44 different materials according to colony and cell morphologies. The ability of each of the isolates to grow at $37^{\circ} \mathrm{C}$ (human body temperature) and $30^{\circ} \mathrm{C}$ was investigated. Fifty-seven isolates grew at $37^{\circ} \mathrm{C}$ as well as $30^{\circ} \mathrm{C}$. The remaining eighty-seven isolates showed weak or no growth at $37^{\circ} \mathrm{C}$. The strains able to grow at both temperatures were selected for further investigation. One of the important criteria for the selection of probiotic yeasts is the ability to grow at $37^{\circ} \mathrm{C}$ (Van der Aa Kühle et al., 2005). Some researchers investigated growth at $37^{\circ} \mathrm{C}$ as the first step of probiotic selection in yeast isolates from traditional Indian foods (Syal \& Vohra, 2013), infant feces and feta cheese (Psomas et al., 2001).

Recently, there is a growing interest in the isolation of microbial EPSs. This compound has been found to have many different industrial applications because of its wide diversity instructural and chemical properties. When added to food, EPSs can positively improve the rheological properties and sensory qualities of the final product (Ramirez, 2016). Moreover, the roles of EPSs in probiotic activities have been determined to be important; some of these includes prebiotic potential, ability to adhese to the intestinal epithelium (Sarkaya et al., 2016), and contributions to human health (Ramirez, 2016), as well as antioxidant, antitumor, antiaging and immunostimulant activities (Cheng et al., 2012; Kšonžeková et al., 2016). Consequently, EPS producing probiotic cultures are reported to positively contribute to human health. Syal \& Vohra (2013) mentioned that $S$. cerevisiae strains and some other yeast strains isolated from traditional fermented food products have the EPS producing capacity. For these reasons, ability to grow at $37^{\circ} \mathrm{C}$ and EPS producing capacity were conducted for preselection of the isolates. In this study, thirty-five of the natural isolates and ten isolates from commercial products survived at $37^{\circ} \mathrm{C}$ and also were shown to be EPS producers by the qualitative method described above. These isolates were selected for use in the investigation of further probiotic properties. This initial screening decreased the number of yeasts to be identified and investigated for other probiotic properties.

A total of forty five isolates were identified by sequencing the D1/D2 domains of the large subunit of the 26S rRNA gene. All isolates (SB codes) from commercial products were identified as S. cerevisiae. The isolates T8-3C from chicken feces and P25-1 from cheese samples were also identified as $S$. cerevisiae. Sequence analyses of the yeast isolates extracted from different materials revealed that six of the strains belonged to Kazachstania bovina, five to K. marxianus, four to Metschnikowia pulcherrima, three to Candida albicans and Pichia kluyveri each, two to Clavispora lusitaniae, Hanseniaspora opuntiae, Hanseniaspora uvarum and Metschnikowia sp. each, and one to Candida corpophila, Candida diddensiae, Meyerozyma carribbica, Wickerhamomyces anomalus each.

According to García-Hernández et al. (2012), nine yeasts from broiler excreta were isolated and selected using biochemical assays and then identified as Trichosporon asahii (LV-2, LV-3, LV-4; LV-10, LV-11), Kodamaea ohmeri (LV-9), Candida pelliculosa (LV-6, LV-7) and Candida krusei/inconspicua. Similarly, Melo Pereira et al. (2014) isolated yeasts from coffee beans by observing their colony morphologies, analysis of rRNA genes, and using some biochemical tests. The yeast strains were identified as Pichia anomala, Pichia fermentans, D. hansenii, Candida sp., Candida glabrata, Candida zeylanoides, Candida maris, C. inconspicua, Candida magnolia, C. lusitaniae, Yarrowia lipolytica, Sporobolomyces roseus, K. marxianus and Torulaspora delbrueckii. In our study, C. lusitaniae and K. marxicianus were also identified.

\subsection{Survival rate of isolates in simulated gastric juice}

All of the forty-five yeasts could survive in simulated gastric juice at $\mathrm{pH} 2.5$ for $2.5 \mathrm{~h}$. Survival rates were consistently higher than $90 \%$. Isolation sources and identification results and log reduction at $\mathrm{pH} 2.5$ for $2.5 \mathrm{~h}$ of the strains are given in Table 1.

The reduction was determined less than $1 \log$ for all yeasts. Survival of both yeasts was similar, showing a reduction of less than $1 \log$ after treatment. After $2.5 \mathrm{~h}$ incubation at $\mathrm{pH} 2.5$, fifteen of thirty five yeasts from natural samples showed good viability; 8 and 4 of the yeasts showed $0.20-0.50$ and $0.5-0.7 \log _{10} \mathrm{CFU} / \mathrm{mL}$ reduction, respectively and the decrease of the 8 yeasts count was just 0.1-0.2 $\log _{10} \mathrm{CFU} / \mathrm{mL}$. While seven of the yeasts from commercial preparates survived at the same number, three of the strains showed 0.1-0.2 $\log _{10} \mathrm{CFU} / \mathrm{mL}$ decrease.

According to Syal \& Vohra (2013), similar results have been reported by several in vitro studies, especially in the yeasts belonging to the species of Saccharomyces, Debaryomyces and Kluyveromyces. Similar results have been reached by using yeasts isolated from broiler excreta; the strains were also capable of surviving and growing under stress conditions such as $2.0,2.5$ and $3.0 \mathrm{pH}$ and $0.3-0.6 \%$ bile salts concentrations with survival rates higher than 98\% (García-Hernández et al., 2012). Van der Aa Kühle et al. (2005) also demonstrated that all yeasts survived after $4 \mathrm{~h}$ of incubation at $\mathrm{pH} 2.5$. All tested yeasts isolated from chicken feces and kefirs showed high survival for $8 \mathrm{~h}$ of incubation at pH 2.5 (Rajkowska \& Kunicka-Styczynska, 2010).

\subsection{EPS production}

EPS production of the forty-five isolates varied almost tenfold, between 27.95 and $275.22 \mathrm{mg} / \mathrm{L}$. According to the findings, EPS production of the strains isolated from commercial yeasts was between 249-275 mg/L. S. cerevisia T8-3C and P25-1, K. bovina T1-3H produced EPS more than $250 \mathrm{mg} / \mathrm{L}$, whereas eight strains produced EPS between 200 and $250 \mathrm{mg} / \mathrm{L}$. The EPS production of S. cerevisiae T8-3C and S. cerevisiae P25-1 showed almost the same level of EPS production with commercial S. cerevisiae 
Table 1. Isolation sources, molecular identification and $\log$ reduction at $\mathrm{pH} 2.5$ for $2.5 \mathrm{~h}$ of the strains.

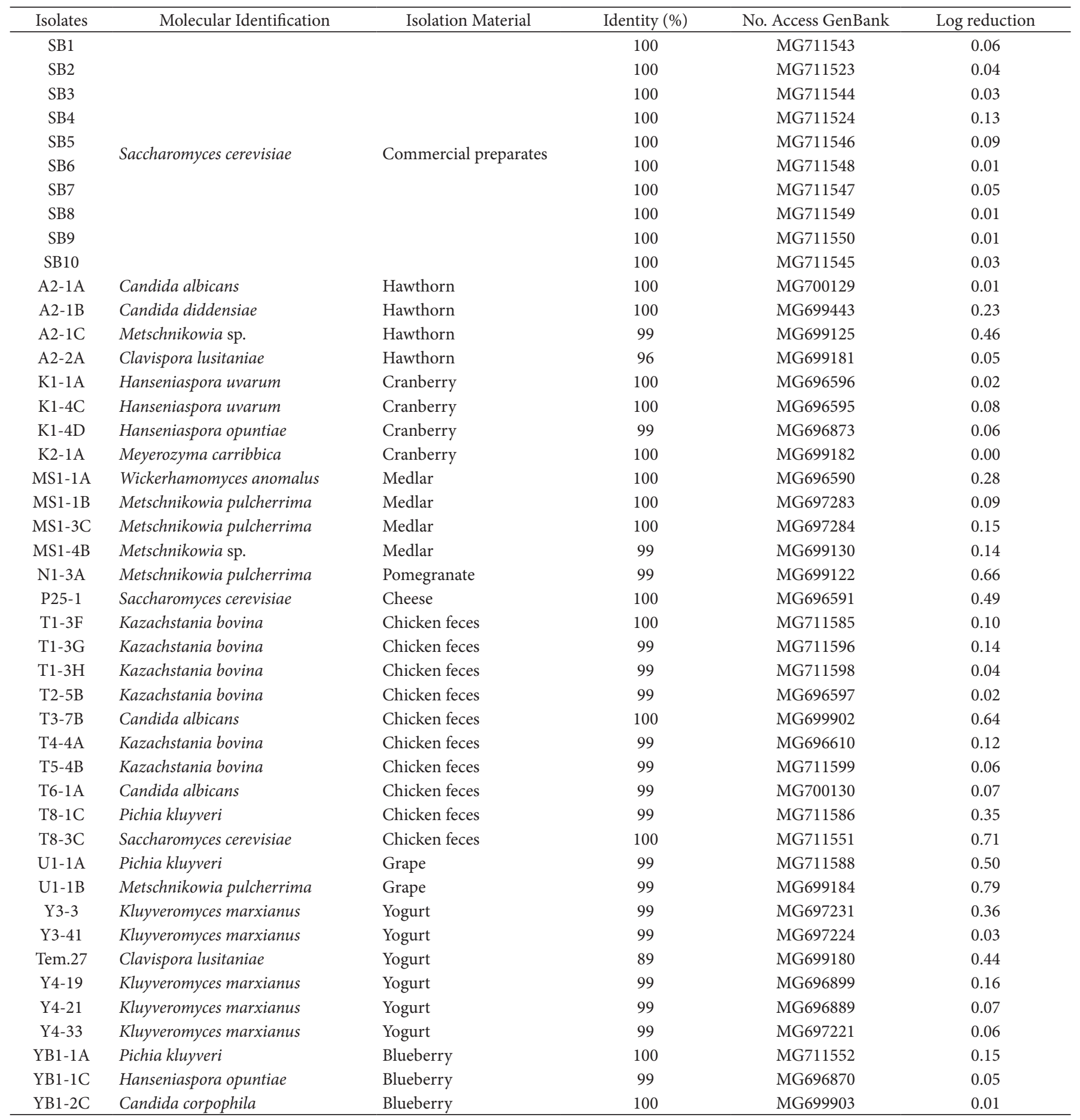

strains (represented by SB codes) as 272.53 and $264.63 \mathrm{mg} / \mathrm{L}$, respectively. EPS production levels are shown in the Figure 1. The EPS production of eleven yeasts; P. kluyveri YB1-1A, S. cerevisiae T8-3C and P25-1, K. bovina T1-3H, T2-5B and T5-4B, K. marxianus Y3-3 and Y4-19, C. albicans A2-1A and T6-1A, C. lusitaniae 7-27 was higher than $200 \mathrm{mg} / \mathrm{L}$. Seven yeasts; C. lusitaniae A2-2A, K. bovina T1-3G, C. corpophila YB1-2C, M. carribbica K2-1A, H. opuntiae YB1-1C, M. pulcherrima U1-1B, W. anomalus MS1-1A produced less than $100 \mathrm{mg} / \mathrm{L}$ EPS.
Many bacteria and yeasts are able to produce EPS, which may show variations in monomer composition, types of branching, and molecular weight. Therefore, the functionality of EPSs produced from microorganisms is immensely varied (Schmid et al., 2016). Gientka et al. (2016) investigated the influence of carbon sources on EPS biosynthesis of the strains Candida famata and Candida guilliermondii isolated from kefirs. The strains were determined to be good EPS producers in their previous study (Gientka \& Madejska, 2013). EPS production 


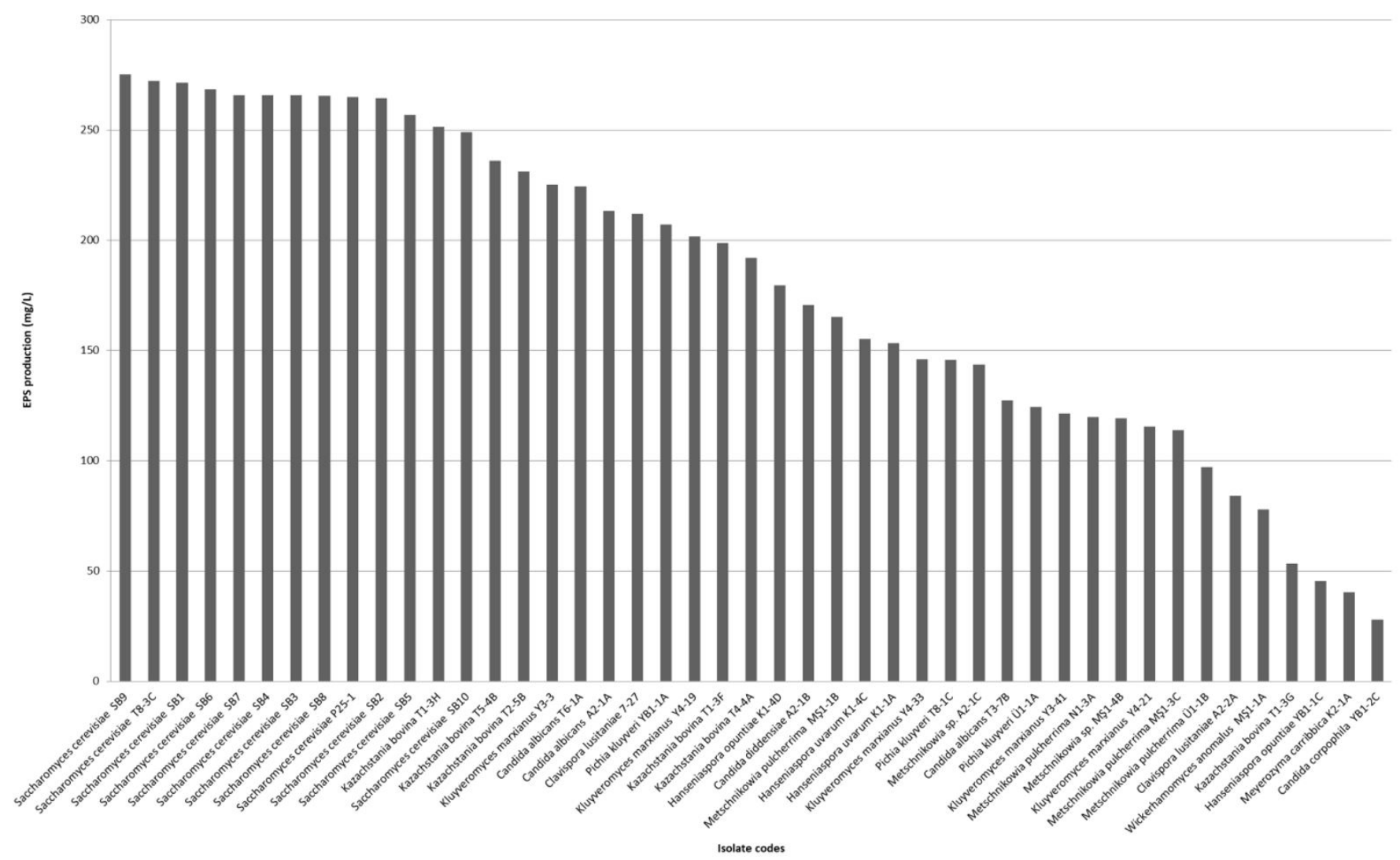

Figure 1. EPS production of isolates.

resulting from growth on different carbon sources ranged from 4.13 to $7.15 \mathrm{~g} / \mathrm{L}$. The highest biomass yield was reported for C. guilliermondii after cultivation on maltose and the maximum EPS production was determined as 0.505 and $0.321 \mathrm{mg} / \mathrm{L}$ for C. guilliermondii and C. famata, respectively. In another research, Ghada et al. (2012) investigated Rhodotorula glutinins isolated from soil, and they determined the optimum culture conditions of EPS synthesis. Maximum EPS production was $2.6 \mathrm{~g} / \mathrm{L}$ and the specific production was $0.34 \mathrm{~g} / \mathrm{g}$ based on dry weight cell with 0.1 of consumed glucose. Review of the literature indicate that EPS production efficiency varies heavily depending on the ambient conditions to which the isolates are subjected (Schmid et al., 2016). Further optimization studies are underway for EPS production of yeasts tested in the present study.

\subsection{Autoaggregation/coaggregation assays}

The capability of forming aggregates is one of the most desirable characteristics of a potential probiotic microorganism, because aggregation of microorganisms affects microbial adherence to the intestines, thus providing potential competitive advantage in the colonization of the GI tract (García-Cayuela et al., 2014). Binetti et al. (2013) described the values of autoaggregation in percentages; $<30 \%$ being low, between 30 and $60 \%$ being intermediate, and $>60 \%$. Prior research studies have used various time intervals and total incubation periods (Syal \& Vohra, 2013;
Ogunremi et al., 2015). In our study, autoaggregation (\%) abilities of the strains were measured every $1 \mathrm{~h}$ over a period of $5 \mathrm{~h}$.

Most of the strains showed similar mean values of autoaggregation around $90 \%$ after $5 \mathrm{~h}$ incubation. Only four isolates (M. pulcherrima MS1-1B and MS1-3C, K. bovina T1-3G, P. kluyveri U1-1A) exhibited autoaggregation abilities below $90 \%$ after $5 \mathrm{~h}$. The autoaggregation of commercial isolates and the other isolates from natural samples were determined as 56.64-93.97 and 41.85-97.59\%, respectively after $2 \mathrm{~h}$ incubation at room temperature (Figure 2). The results obtained by Gil-Rodríguez et al. (2015) showed autoaggregation for yeasts isolated from foods at 1.1 to $85.8 \%$ at $2 \mathrm{~h}$, and from 83.3 to $99.8 \%$ at $24 \mathrm{~h}$, the results suggesting that autoaggregation percentages are strongly strain dependent.

At $5 \mathrm{~h}$ of incubation at room temperature C. lusitaniae A2-2A, K. bovina T1-3F, T2-5B, T4-4A, H. opuntiae YB1-1C, $S$. cerevisiae $\mathrm{T} 8-3 \mathrm{C}$ and $\mathrm{SB} 7$ showed autoaggregation higher than $90 \%$. S. cerevisiae SB1, SB3, H. uvarum K1-1A and K1-4C, C. diddensiae A2-1B, P. kluyveri U1-1A and K. marxianus Y3-41 showed autoaggregation below 60\%. Binetti et al. (2013) examined the autoaggregation properties of 20 yeast isolates from cheese starters and most of the isolates showed intermediate autoaggregation values. Chelliah et al. (2016) investigated the probiotic characteristics of Pichia kudriavzevii isolated from frozen idli batter in India, and they determined the autoaggregation values as $59.12 \%$ after $5 \mathrm{~h}$ incubation and $81.23 \%$ after $24 \mathrm{~h}$ incubation. 


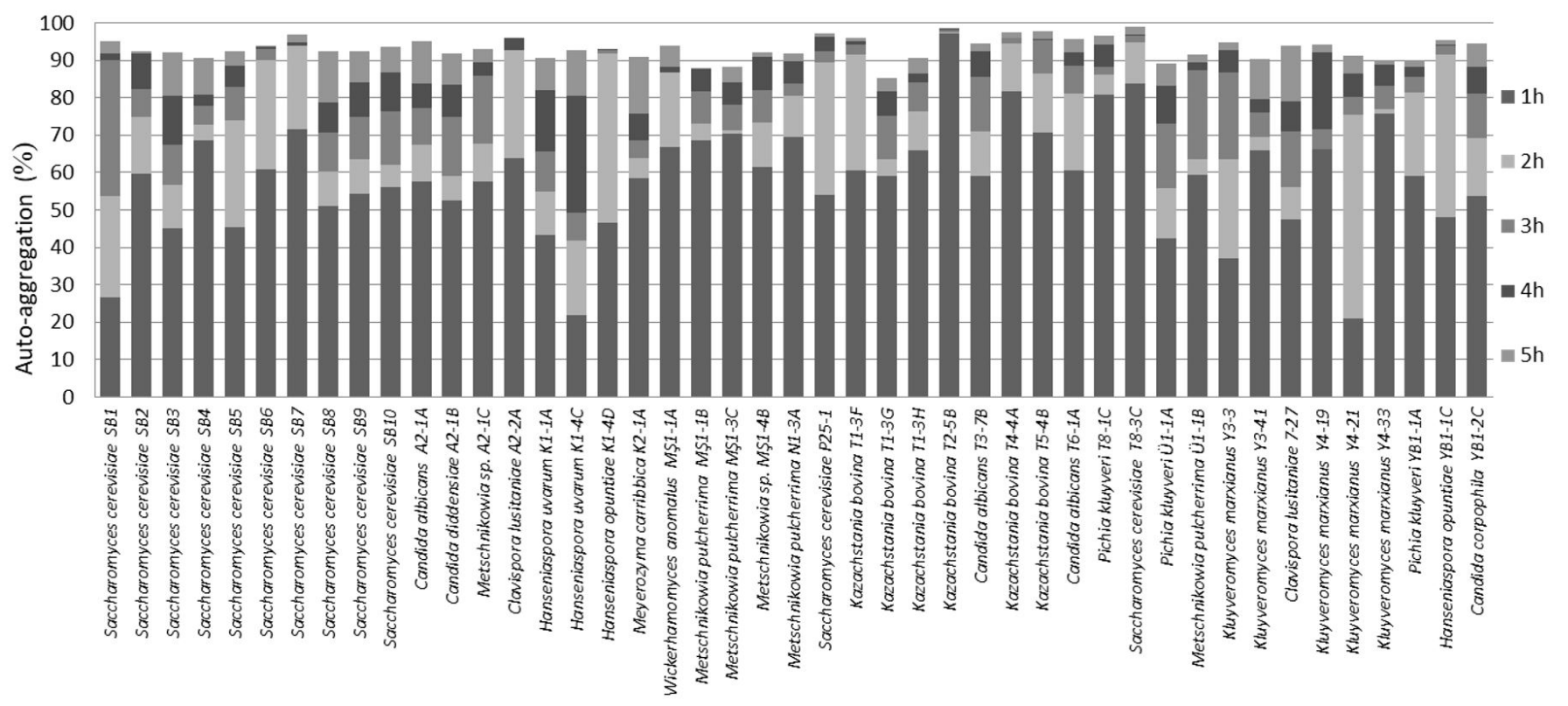

Isolate codes

Figure 2. Auto-aggregation of isolates.

Table 2. Co-aggregation ability after $5 \mathrm{~h}$ incubation at room temperature (\%).

\begin{tabular}{lcccc}
\hline \multicolumn{1}{c}{ Isolate code } & E.coli O157:H7 & S. Typhimurium & S.auerus & L. monocytogenes \\
\hline Saccharomyces cerevisiae SB10 & $26.38 \pm 0.012$ & $21.68 \pm 0.015$ & $27.34 \pm 0.010$ & $14.71 \pm 0.002$ \\
Saccharomyces cerevisiae SB-7 & $20.79 \pm 0.008$ & $20.97 \pm 0.002$ & $26.19 \pm 0.013$ & $13.02 \pm 0.006$ \\
Saccharomyces cerevisiae SB-9 & $27.85 \pm 0.005$ & $26.88 \pm 0.009$ & $32.94 \pm 0.012$ & $12.13 \pm 0.017$ \\
Pichia kluyveri YB1-1A & $18.21 \pm 0.012$ & $15.32 \pm 0.037$ & $23.67 \pm 0.015$ & $15.89 \pm 0.002$ \\
Pichia kluyveri T8-1C & $21.00 \pm 0.008$ & $21.49 \pm 0.012$ & $32.37 \pm 0.003$ & $19.68 \pm 0.008$ \\
Saccharomyces cerevisiae T8-3C & $16.04 \pm 0.004$ & $12.60 \pm 0.002$ & $28.49 \pm 0.009$ & $15.94 \pm 0.008$ \\
Saccharomyces cerevisiae P25-1 & $22.16 \pm 0.002$ & $26.23 \pm 0.008$ & $35.82 \pm 0.016$ & $16.95 \pm 0.008$ \\
\hline
\end{tabular}

Seddik et al. (2016) aimed to show the yeast diversity in feces of Algerian infants, aged between 1 and 24 months. The autoaggregation rate of S. cerevisiae P9L1 was $22.5 \pm 2.6$ and $45.9 \pm 3.4 \%$ after 2 and $4 \mathrm{~h}$ of incubation, respectively. Based on autoaggregation ability, three strains of S. cerevisiae (SB7, SB9 and SB10) from commercial isolates, two strains of $P$. kluyveri (YB1-1A, T8-1C) and two strains of $S$. cerevisiae (T8-3C, P25-1) from natural sources were examined for coaggregation values against $S$. aureus (ATCC 25923), L. monocytogenes (RSKK 472), E. coli O157:H7 (ATCC 35150) and S. Typhimurium (ATCC 700408). The results are shown in Table 2. The highest coaggregation ability for the tested pathogens was observed with S. aureus (ATCC 25923), between 23.67 and $35.82 \%$ mean values. The highest coaggregation ability was determined for the P25-1 strain with S. aureus (ATCC 25923). Coaggregation percentage of isolates with E. coli O157:H7 (ATCC 35150) ranged from 16.04 to $27.85 \%$ mean values. Coaggregation mean values with L. monocytogenes (RSKK 472) and S.Typhimurium (ATCC 700408) ranged from 12.13 to $19.68 \%$ and from 12.60 to $26.88 \%$, respectively. In addition, Binetti et al. (2013) studied the coaggregation properties of isolates with E. coli V517 and Salmonella Enteritidis OMS-Ca, their results indicated that tested isolates showed the highest coaggregation values with S. Enteritidis OMS-Ca.

\section{Conclusion}

Probiotics play a critical and vital role in human nutrition. In recent years, new strain isolation, characterization and verification of potential health benefits particularly related with probiotic traits have been a very attractive area for researchers. Probiotic properties are strain specific, therefore new strains must be well characterized. In this study, good survival in gastric juice, high percentages of autoaggregation/coaggregation and production of EPS were determined for some of the natural isolates investigated. In this study, natural S. cerevisiae strains showed high as EPS production as much as commercial isolates and had good features in terms of autoaggregation and coaggregation. Pichia kluyveri YB1-1A and Pichia kluyveri T8-1C were aggregated in the first hour of incubation period. Even though the strains were not able to produce EPS as much as S. cerevisiae, they produced EPS between 100 to $150 \mathrm{mg} / \mathrm{L}$. The results indicated that, among the isolated strains, S. cerevisiae T8-3C and P25-1, Pichia kluyveri YB1-1A and T8-1C showed notable potential probiotic properties. These yeasts were selected to be used in the present study since they have been verified to be reliable for food industry and biotechnological applications. This research represents a study of probiotic yeast selection; to declare them 
as effective probiotics, these strains would undoubtedly require further studies and animal trials. Food and pharmacy industries may benefit from these strains as new food supplements or pharmaceutical preparations.

\section{Acknowledgements}

We thank Republic of Turkey, Ministry of Science, Industry and Technology and Süleyman Demirel University Scientific Research Council which supported this research with San-Tez Project No. 0480.STZ.2013-2 and Project No. 3793-D2-13, respectively.

\section{References}

Binetti, A., Carrasco, M., Reinheimer, J., \& Suárez, V. (2013). Yeasts from autochthonal cheese starters: technological and functional properties. Journal of Applied Microbiology, 115(2), 434-444. http:// dx.doi.org/10.1111/jam.12228. PMid:23600736.

Cassanego, D., Richards, N., Valente, P., Mazutti, M., \& RamírezCastrillón, M. (2017). Identification by PCR and evaluation of probiotic potential in yeast strains found in kefir samples in the city of Santa Maria, RS, Brazil. Food Science and Technology, 38(Suppl. 1), 59-65. http://dx.doi.org/10.1590/1678-457x.13617.

Chelliah, R., Ramakrishnan, S. R., Prabhu, P. R., \& Antony, U. (2016). Evaluation of antimicrobial activity and probiotic properties of wild-strain Pichia kudriavzevii isolated from frozen idli batter. Yeast, 33(8), 385-401. http://dx.doi.org/10.1002/yea.3181. PMid:27370793.

Chen, X., Yang, G., Song, J.-H., Xu, H., Li, D., Goldsmith, J., Zeng, H., Parsons-Wingerter, P. A., Reinecker, H. C., \& Kelly, C. P. (2013). Probiotic yeast inhibits VEGFR signaling and angiogenesis in intestinal inflammation. PLoS One, 8(5), e64227. http://dx.doi. org/10.1371/journal.pone.0064227. PMid:23675530.

Cheng, F.-S., Wang, H., Zhang, X., Luo, Y.-J., \& Dong, P.-C. (2012). Effects of yeast polysaccharide on immune enchancement and production performance of rats. Journal of Animal and Veterinary Advances, 11(11), 1800-1804. http://dx.doi.org/10.3923/javaa.2012.1800.1804.

Corcoran, B. M., Stanton, C., Fitzgerald, G. F., \& Ross, R. P. (2005). Survival of probiotic lactobacilli in acidic environments is enhanced in the presence of metabolizable sugars. Applied and Environmental Microbiology, 71(6), 3060-3067. http://dx.doi.org/10.1128/ AEM.71.6.3060-3067.2005. PMid:15933002.

Dubois, M., Gilles, K. A., Hamilton, J. K., Rebers, P. A., \& Smith, F. (1956). Colorimetric method for determination of sugars and related substances. Analytical Chemistry, 28(3), 350-356. http://dx.doi. org/10.1021/ac60111a017.

Fakruddin, M., Hossain, M. N., \& Ahmed, M. M. (2017). Antimicrobial and antioxidant activities of Saccharomyces cerevisiae IFST062013, a potential probiotic. BMC Complementary and Alternative Medicine, 17(1), 64. http://dx.doi.org/10.1186/s12906-017-1591-9. PMid:28109187.

Fleet, G. H. (2007). Yeasts in foods and beverages: impact on product quality and safety. Current Opinion in Biotechnology, 18(2), 170-175. http://dx.doi.org/10.1016/j.copbio.2007.01.010. PMid:17275276.

Food and Agriculture Organization of the United Nations - FAO. World Health Organization - WHO. (2002). Guidelines for the evaluation of probiotics in food: report of a Joint FAO/WHO working group on drafting guidelines for the evaluation of probiotics in food. London: FAO/WHO.

García-Cayuela, T., Korany, A. M., Bustos, I., de Cadiñanos, L. P. G., Requena, T., Peláez, C., \& Martínez-Cuesta, M. C. (2014).
Adhesion abilities of dairy Lactobacillus plantarum strains showing an aggregation phenotype. Food Research International, 57, 44-50. http://dx.doi.org/10.1016/j.foodres.2014.01.010.

García-Hernández, Y., Rodríguez, Z., Brandão, L. R., Rosa, C. A., Nicoli, J. R., Elías Iglesias, A., Peréz-Sanchez, T., Salabarría, R. B., \& Halaihel, N. (2012). Identification and in vitro screening of avian yeasts for use as probiotic. Research in Veterinary Science, 93(2), 798802. http://dx.doi.org/10.1016/j.rvsc.2011.09.005. PMid:22047814.

Ghada, S. I., Manal, G. M., Mohsen, M. S. A., \& Eman, A. G. (2012). Production and biological evaluation of exopolysaccharide from isolated Rhodotorula glutinins. Australian Journal of Basic and Applied Sciences, 6(3), 401-408.

Gientka, I., \& Madejska, A. (2013). Evaluate the ability of the yeast strains isolated from kefir for the synthesis of extracellular polymers. Agricultural Sciences Problem Issues, 574, 19-27.

Gientka, I., Bzducha-Wróbel, A., Stasiak-Różańska, L., Bednarska, A. A., \& Błażejak, S. (2016). The exopolysaccharides biosynthesis by Candida yeast depends on carbon sources. Electronic Journal of Biotechnology, 22, 31-37. http://dx.doi.org/10.1016/j.ejbt.2016.02.008.

Gil-Rodríguez, A. M., Carrascosa, A. V., \& Requena, T. (2015). Yeasts in foods and beverages: in vitro characterisation of probiotic traits. Lebensmittel-Wissenschaft + Technologie, 64(2), 1156-1162. http:// dx.doi.org/10.1016/j.lwt.2015.07.042.

Gotcheva, V., Hristozova, E., Hristozova, T., Guo, M., Roshkova, Z., \& Angelov, A. (2002). Assessment of potential probiotic properties of lactic acid bacteria and yeast strains. Food Biotechnology, 16(3), 211-225. http://dx.doi.org/10.1081/FBT-120016668.

Hu, X. Q., Liu, Q., Hu, J. P., Zhou, J. J., Zhang, X., Peng, S. Y., Peng, L. J., $\&$ Wang, X. D. (2018). Identification and characterization of probiotic yeast isolated from digestive tract of ducks. Poultry Science, 97(8), 2902-2908. http://dx.doi.org/10.3382/ps/pey152. PMid:29762784.

Kawahata, M., Fujii, T., \& Iefuji, H. (2007). Intraspecies diversity of the industrial yeast strains Saccharomyces cerevisiae and Saccharomyces pastorianus based on analysis of the sequences of the internal transcribed spacer (ITS) regions and the D1/D2 region of $26 \mathrm{~S}$ rDNA. Bioscience, Biotechnology, and Biochemistry, 71(7), 1616-1620. http:// dx.doi.org/10.1271/bbb.60673. PMid:17617725.

Kos, B., Šušković, J., Vuković, S., Šimpraga, M., Frece, J., \& Matošić, S. (2003). Adhesion and aggregation ability of probiotic strain Lactobacillus acidophilus M92. Journal of Applied Microbiology, 94(6), 981-987. http://dx.doi.org/10.1046/j.1365-2672.2003.01915.x. PMid:12752805.

Kšonžeková, P., Bystrický, P., Vlčková, S., Pätoprstý, V., Pulzová, L., Mudroňová, D., Kubašková, T., Csank, T., \& Tkáčiková, L. (2016). Exopolysaccharides of Lactobacillus reuteri: Their influence on adherence of E. coli to epithelial cells and inflammatory response. Carbohydrate Polymers, 141, 10-19. http://dx.doi.org/10.1016/j. carbpol.2015.12.037. PMid:26876991.

Kuncheva, M., Pavlova, K., Panchev, I., \& Dobreva, S. (2007). Emulsifying power of mannan and glucomannan produced by yeasts. International Journal of Cosmetic Science, 29(5), 377-384. http://dx.doi.org/10.1111/j.1468-2494.2007.00393.x. PMid:18489371.

Marshall, V. M., \& Rawson, H. L. (1999). Effects of exopolysaccharideproducing strains of thermophilic lactic acid bacteria on the texture of stirred yoghurt. International Journal of Food Science \& Technology, 34(2), 137-143. http://dx.doi.org/10.1046/j.1365-2621.1999.00245.x.

Melo Pereira, G. V., Soccol, V. T., Pandey, A., Pedroni Medeiros, A. B., Andrade Lara, J. M. R., Gollo, A. L., \& Soccol, C. R. (2014). Isolation, selection and evaluation of yeasts for use in fermentation of coffee beans by the wet process. International Journal of Food Microbiology, 
188, 60-66. http://dx.doi.org/10.1016/j.ijfoodmicro.2014.07.008. PMid:25087206.

Moradi, R., Nosrati, R., Zare, H., Tahmasebi, T., Saderi, H., \& Owlia, P. (2018). Screening and characterization of in-vitro probiotic criteria of Saccharomyces and Kluyveromyces strains. Iranian Journal of Microbiology, 10(2), 123-131. PMid:29997753.

Moslehi-Jenabian, S., Lindegaard, L., \& Jespersen, L. (2010). Beneficial effects of probiotic and food borne yeasts on human health. Nutrients, 2(4), 449-473. http://dx.doi.org/10.3390/nu2040449. PMid:22254033.

Muccilli, S., \& Restuccia, C. (2015). Bioprotective role of yeasts. Microorganisms, 3(4), 588-611. http://dx.doi.org/10.3390/ microorganisms3040588. PMid:27682107.

National Center for Biotechnology Information - NCBI. (2018). Retrieved from http://www.ncbi.nlm.nih.gov

Ogunremi, O. R., Sanni, A. I., \& Agrawal, R. (2015). Probiotic potentials of yeasts isolated from some cereal-based Nigerian traditional fermented food products. Journal of Applied Microbiology, 119(3), 797-808. http://dx.doi.org/10.1111/jam.12875. PMid:26095794.

Pavlova, K., Koleva, L., Kratchanova, M., \& Panchev, I. (2004). Production and characterization of an exopolysaccharide by yeast. World Journal of Microbiology \& Biotechnology, 20(4), 435-439. http://dx.doi. org/10.1023/B:WIBI.0000033068.45655.2a.

Psomas, E., Andrighetto, C., Litopoulou-Tzanetaki, E., Lombardi, A., \& Tzanetakis, N. (2001). Some probiotic properties of yeast isolates from infant faeces and feta cheese. International Journal of Food Microbiology, 69(1-2), 125-133. http://dx.doi.org/10.1016/S01681605(01)00580-3. PMid:11589551.

Rajkowska, K., \& Kunicka-Styczynska, A. (2010). Probiotic properties of yeasts isolated from chicken feces and kefirs. Polish Journal of Microbiology, 59(4), 257-263. PMid:21466043.

Ramirez, M. A. J. R. (2016). Characterization and safety evaluation of exopolysaccharide produced by Rhodotorula minuta BIOTECH 2178. International Journal of Food Engineering, 2(1), 31-35.

Sarıkaya, H., Aslım, B., \& Yüksekdağ, Z. N. (2016). Assessment of anti-biofilm activity and bifidogenic growth stimulator (bgs) effect of lyophilized exopolysaccharides (l-epss) from lactobacilli strains. International Journal of Food Properties, 20(2), 362-371. http://dx.doi. org/10.1080/10942912.2016.1160923.

Schmid, J., Fariña, J., Rehm, B., \& Sieber, V. (2016). Editorial: microbial exopolysaccharides: from genes to applications. Frontiers in Microbiology, 7(308), 1-3. http://dx.doi.org/10.3389/fmicb.2016.00308. PMid:27014231.

Seddik, H. A., Ceugniez, A., Bendali, F., Cudennec, B., \& Drider, D. (2016). · Yeasts isolated from Algerian infants's feces revealed a burden of Candida albicans species, Non-Albicans candida species and Saccharomyces cerevisiae. Archives of Microbiology, 198(1), 7181. http://dx.doi.org/10.1007/s00203-015-1152-x. PMid:26404657.

Sourabh, A., Kanwar, S. S., \& Sharma, O. P. (2011). Screening of indigenous yeast isolates obtained from traditional fermented foods of Western Himalayas for probiotic attributes. Journal of Yeast and Fungal Research, 2(8), 117-126.

Suarez, C., \& Guevara, C. A. (2018). Probiotic use of yeast Saccharomyces cerevisiae in animal feed. Research Journal of Zoology, 1(1).

Suvarna, S., Dsouza, J., Ragavan, M. L., \& Das, N. (2018). Potential probiotic characterization and effect of encapsulation of probiotic yeast strains on survival in simulated gastrointestinal tract condition. Food Science and Biotechnology, 27(3), 745-753. http://dx.doi. org/10.1007/s10068-018-0310-8. PMid:30263800.

Syal, P., \& Vohra, A. (2013). Probiotic potential of yeasts isolated from traditional Indian fermented foods. International Journal of Microbiology Research, 5(2), 390-398. http://dx.doi.org/10.9735/09755276.5.2.390-398

Van der Aa Kühle, A., Skovgaard, K., \& Jespersen, L. (2005). In vitro screening of probiotic properties of Saccharomyces cerevisiae var. boulardii and food-borne Saccharomyces cerevisiae strains. International Journal of Food Microbiology, 101(1), 29-39. http:// dx.doi.org/10.1016/j.ijfoodmicro.2004.10.039. PMid:15878404.

Xu, J., Li, Y., Yang, Z., Li, C., Liang, H., Wu, Z., \& Pu, W. (2018). Yeast probiotics shape the gut microbiome and improve the health of early-weaned piglets. Frontiers in Microbiology, 9, 2011. http://dx.doi. org/10.3389/fmicb.2018.02011. PMid:30210480. 